\title{
O Ensino Superior e a Formação de Professores com Ênfase nas Engenharias
}

\author{
Luciana Guidon Coelho, José Aquiles Baesso Grimoni* \\ Departamento de Engenharia de Energia e Automação Elétricas da Escola Politécnica da Universidade de São Paulo
}

* Autor para correspondência: aquiles@pea.usp.br

\section{RESUMO}

O objetivo deste artigo é discutir e promover a reflexão sobre o papel do ensino superior e da docência, a necessidade da formação e desenvolvimento profissional de professores e a importância da educação em engenharia como área de conhecimento. As mudanças ocorridas no ensino superior brasileiro e a demanda por mais engenheiros mais bem qualificados, principalmente no que tange às competências transversais, foram a motivação para este trabalho. A mudança na formação dos engenheiros requer diversas transformações, sobretudo nas estratégias das aulas, o que claramente passa pela formação do corpo docente e por modificações institucionais.

Palavras-Chave: Formação de Professores; Ensino Superior; Educação em Engenharia.

\begin{abstract}
The purpose of this paper is to discuss and promote reflection on the role of higher education and teaching, the need for teachers' professional development and the importance of engineering education research area. The changes that took place in Brazilian higher education and the demand for more qualified engineers, especially with regard to soft skills, were the motivation for this paper. The change in engineers' graduation requires a number of changes, mainly in the classroom strategies, which clearly involves faculty training and institutional changes.
\end{abstract}

Keywords: Teacher Education; Higher Education; Engineering Education.

\section{Introdução: o Papel do Ensino Superior e da Docência}

Este trabalho apresenta uma revisão de literatura sobre o papel do ensino superior e da docência, dando especial foco para a educação em engenharia e a formação e desenvolvimento profissional de professores, dois temas muito presentes em eventos e publicações internacionais.

Atualmente, as universidades foram convertidas em recursos de desenvolvimento social e econômico dos países, e assim passam a estar submetidas às mesmas leis políticas e econômicas dos outros recursos (ZABALZA, 2004).

A instituição universidade conta com quase nove séculos e está presente no continente europeu muito tempo antes até mesmo do descobrimento de diversos países. Durante a Idade Média, a universidade se estruturava em torno das aulas magistrais, e a indissociabilidade entre ensino e pesquisa e a produção interdisciplinar do conhecimento eram características marcantes daquela época. Até o século XIX a universidade não passou por muitas transformações, porém, no início do mesmo século, as mudanças se iniciaram em função de dois novos paradigmas organizacionais: o modelo napoleônico ${ }^{1}$ e o modelo humboldtiano ${ }^{2}$ (ALMEIDA, 2012). A partir do século XIX, a universidade passou a problematizar a cultura europeia e abriu-se para outras culturas, o que permitiu a coexistência da das humanidades com a cultura científica (MORIN, 2000).

O crescente volume de conhecimentos altamente fragmentados tem relação direta com a dinâmica vivida pela universidade nos últimos 150 anos, fruto do papel que lhe tem sido atribuído (ALMEIDA, 2012). O papel da universidade é o de ser um lugar de indagação (busca e pesquisa) organizada, dedicada a gerir a incerteza (BARNETT, 2002). 
As políticas universitárias contemporâneas assim como todos os elementos articuladores entre universidade e sociedade apresentam-se fortemente influenciados pelas relações do capitalismo globalizado. Como se observa a obrigatoriedade de geração de conhecimento para o mercado, o ensino superior parece ter a obrigação de formar profissionais para nichos de mercado específicos e, para tanto, parece ser cada vez mais comum que a educação também seja comercializada como uma mercadoria. Todas essas questões decorrentes da globalização e da internacionalização são extremamente complexas e desafiadoras quer para as universidades, quer para a sociedade (ALMEIDA, 2012).

No Brasil, a reforma do Estado definiu a universidade como uma organização social, e não como uma instituição social, o que a universidade realmente é. O fato é que uma organização difere de uma instituição por se definir por uma prática social determinada de acordo com a sua instrumentalidade: refere-se ao conjunto de meios administrativos particulares para a obtenção de um objetivo particular; e não está relacionada a ações articuladas às ideias de reconhecimento externo e interno, de legitimidade interna e externa, mas a operações definidas como estratégias determinadas pelas ideias de eficácia e sucesso no emprego de determinado meio para atingir um objetivo particular que a define (CHAUÍ, 2003).

A universidade se tornou uma "grande empresa" situada no centro da vida econômica e urbana, o que certamente afeta a produção e a difusão do conhecimento. A gestão universitária deve ser repensada; é preciso resgatar a capacidade da universidade de responder e prosperar em meio a um mundo de incertezas radicais. É necessário abandonar a ideia de apenas resolver problemas; os alunos precisam pensar e questionar, considerando-se que a pesquisa carece de mais espaço, porém, com novo sentido e forma (BARNETT, 2002).

De acordo com Chauí (2003, p. 7),

a docência é pensada como habilitação rápida para graduados, que precisam entrar rapidamente num mercado de trabalho do qual serão expulsos em poucos anos, pois se tornam, em pouco tempo, jovens obsoletos e descartáveis; ou como correia de transmissão entre pesquisadores e treino para novos pesquisadores. Transmissão e adestramento. Desapareceu, portanto, a marca essencial da docência: a formação.

O contexto atual do ensino superior, as transformações das universidades, a dinâmica da sociedade e a docência estão intimamente relacionados. A universidade foi reduzida a uma organização, e dela se espera a "produção" de mão de obra qualificada que atenda à demanda do mercado em constante mutação, produtividade científica e altas posições nos rankings nacionais e internacionais (ALMEIDA, 2012; BARNETT, 2002; GHAUÍ, 2003; KRASILGHIK, 2000, 2009).

Há alguns fatores no atual cenário brasileiro de ensino superior que contribuem para a criação de tensões que refletem diretamente nas salas de aula e nas relações dos professores e alunos. Uma das fontes de tensão certamente é o grande aumento da população estudantil que pleiteia acesso ao ensino superior, sendo esse aumento oriundo do "movimento dos excedentes" ocorrido no Brasil na década de 1960, que desencadeou uma grande expansão da rede privada de ensino (KRASILCHIK, 2000, 2009). É importante observar que a massificação da universidade, ou seja, o drástico aumento do número de alunos também se deu fora do Brasil (ZABALZA, 2004).

No Brasil, o aumento de egressos do ensino médio, a valorização da educação superior como credencial para se conseguir um emprego e a possibilidade de mobilização social geram movimentações para melhorar a possibilidade de frequentar a universidade. A resposta para isso tem sido a ampliação de cursos e vagas nas universidades públicas e principalmente nas privadas. Do aumento de vagas e de instituições decorre uma diminuição dos recursos financeiros e humanos, o que acaba por sobrecarregar os professores. $\mathrm{O}$ aumento das vagas leva também à existência de classes muito numerosas, tornando o trabalho dos 
docentes ainda mais complexo (GUNHA, 2000; KRASILCHIK, 2000, 2009).

As universidades públicas e também algumas privadas costumam organizar o trabalho dos professores não apenas de acordo com os dispositivos trabalhistas, mas também em conformidade com as diretrizes de um sistema de carreira docente, para valorizar e reconhecer o mérito acadêmico dos professores no exercício de sua função (SEVERINO, 2009). Porém, o mérito acadêmico tende a ser medido por atividades relacionadas à pesquisa e não ao ensino. Esse fator de tensão também afeta o trabalho dos professores e os desmotiva a melhorarem suas aulas, dada a dicotomia que se propõe entre o ensino e a pesquisa, pois a pesquisa é mais valorizada nas universidades do que a docência. A pesquisa é mais valorizada pelas agências de fomento, muito mais cobrada pelos órgãos internos da própria universidade e também é importante para mantê-la bem colocada em rankings internacionais (KRASILCHIK, 2009).

Cada hora adicional de esforço que um professor dedica à docência provavelmente reduz uma hora de esforço que dedicaria à pesquisa e isso prejudica suas expectativas de carreira e sua remuneração a longo prazo. Existe uma quase perfeita correlação negativa entre as horas de docência e o salário. Os sistemas de reconhecimento e recompensa habitualmente desanimam os professores de levarem a sério a docência [...] (GIBBS, 2004, pp. 16-17).

Embora a universidade seja uma instituição de ensino superior, muitas vezes a docência é considerada secundária, como se não exigisse preparo nem atenção especiais. A preocupação com a docência ainda não se mostra presente em grande parte dos cursos nas universidades, ao contrário da pesquisa, valorizada e incentivada. A atenção ao caráter pedagógico do trabalho docente parece ser algo restrito aos cursos de licenciatura e às Faculdades de Educação (ALMEIDA, 2012; CUNHA, 2009; RIOS, 2011).

Além das atividades de ensino e pesquisa que cabem aos professores, muitas vezes lhes são atribuídas outras funções, como as de gestão de departamentos, negócios (captação de financiamentos e parcerias, por exemplo) e relações institucionais. De todas as atividades citadas, a docência deveria ser a mais importante, por concentrar a tarefa formativa da universidade (ZABALZA, 2004).

Com o intuito de entender melhor o contexto brasileiro, Martins (2000) aponta que, no intervalo de pouco mais de trinta anos, o sistema de ensino do Brasil passou por expressivas mudanças. No início dos anos 1960, como citado anteriormente, havia cerca de uma centena de instituições de ensino superior, a maioria de pequeno porte, vocacionadas para a reprodução de quadros da elite nacional. Nos anos 2000, já existia um número expressivamente maior de instituições. E, neste processo de mudanças, houve a incorporação de um público mais diferenciado socialmente, alunos com perfis diversos, sendo observado um aumento significativo do ingresso de estudantes do gênero feminino, a entrada de alunos já integrados ao mercado de trabalho e o acentuado processo de interiorização e regionalização do ensino.

Os variados perfis de alunos ingressantes no ensino superior também influem na trajetória acadêmica deles. Em função dos diversos perfis, os alunos fazem a transição para o "mundo universitário" de maneiras distintas. Essa transição é um processo de ajuste a um mundo novo e por vezes completamente desconhecido, o que pode acarretar estresse e dificuldades. Nem sempre os alunos chegam preparados às universidades. $\mathrm{O}$ processo de ajuste acadêmico é mais difícil quanto maior for a brecha entre o primeiro ano do curso de graduação e as experiências prévias do aluno. O capital cultural dos estudantes desempenha um papel crucial para suas oportunidades quando ingressam na graduação (EZCURRA, 2009).

Ezcurra (2009) salienta ainda a necessidade de mudanças, principalmente nas políticas institucionais. O objetivo deveria ser uma melhor educação, e não apenas diminuir ou interromper a evasão dos alunos. Dessa maneira, Rué (2009) entende que os professores, munidos de conhecimentos 
pedagógicos, desenvolvem sua própria competência profissional e estão aptos para desenvolver a autonomia na aprendizagem dos alunos, mesmo sendo estes de perfis tão variados.

Há a necessidade de se repensar a docência universitária no sentido de favorecer a permanência e o desenvolvimento acadêmico com sucesso dos alunos com menor capital cultural, isto é, aqueles alunos oriundos de classes econômicas menos favorecidas. Práticas docentes em aula constituem a chave para a permanência estudantil. É preciso haver uma reflexão sobre a prática docente, pois do professor universitário não é exigida a formação pedagógica. Fica evidente que é necessária, no âmbito das Instituições de Ensino Superior, a formação de docentes reflexivos e o favorecimento da constituição de bases pedagógicas para que o professor tenha referências mais amplas para sustentar o trabalho de ensinar dentro de um contexto tão complexo e para alunos tão diversificados (BELLETATI, 2011; EZCURRA, 2009).

\section{Formação de Professores para o Ensino Superior}

A docência no nível superior exige do professor domínio na área pedagógica. Em geral, esse é o ponto mais carente de nossos professores universitários, quando vamos falar em profissionalismo na docência. Seja porque nunca tiveram oportunidade de entrar em contato com essa área, seja porque a veem como algo supérfluo ou desnecessário para sua atividade de ensino (MASETTO, 1998, p. 20).

A docência é uma obrigação do professor de ensino superior e, nas instituições particulares, normalmente a única atividade do professor; mas no caso das instituições públicas não, visto que nestas, eles desenvolvem também seus projetos de pesquisa. Os concursos para ingresso como professor em instituições públicas são essencialmente para o "cargo" de professor, mas aquele que consegue uma vaga, muitas vezes, só tem interesse nas atividades de pesquisa ou acaba se interessando mais por essas atividades por elas serem mais atrativas, valorizadas e muitas vezes mais vantajosas. Duas grandes referências constituem a base que fundamenta a docência: o mundo do trabalho e o universo da pesquisa. No mundo do trabalho, a ideia principal é a de "quem sabe fazer sabe ensinar". Já o universo da pesquisa predomina como preocupação formativa nos cursos de pós-graduação, algo que dificulta o enfrentamento da ênfase historicamente dada à dimensão da pesquisa em detrimento do ensino no contexto das atividades docentes nas universidades. Tais tendências são responsáveis pelo afastamento radical da formação e da atuação docente do campo da pedagogia. $\mathrm{O}$ professor universitário não tem formação voltada para os processos de ensino e aprendizagem, pelos quais é responsável. Quando ele inicia sua vida acadêmica, não há tempo para a aquisição das competências pedagógicas (ALMEIDA, 2012; GAETA \& MASETTO, 2013).

A concepção da docência como um dom carrega o desprestígio da sua condição acadêmica; os conhecimentos pedagógicos são postos em segundo plano e desvalorizados. O campo de formação do docente de todos os níveis, principalmente o universitário, não recebe seu devido valor. Os conhecimentos pedagógicos se constituíram distantes do espaço universitário e só tardiamente alcançaram alguma legitimação científica, visto que o foco da pedagogia sempre foram as crianças, o que criou uma imagem distorcida da amplitude e complexidade da pedagogia (CUNHA, 2009a).

A docência é uma atividade complexa, e tanto professores como as instituições precisam se conscientizar desse fato; ela exige uma preparação cuidadosa, demanda múltiplos saberes que precisam ser apropriados e compreendidos em suas relações. Infelizmente, o conhecimento pedagógico tem pouco prestígio na universidade, além de que os assuntos relacionados à pedagogia estão atrás de barreiras cognitivas, como as metodologias, os termos, entre outros. A pedagogia universitária é um espaço de conexão de conhecimentos e culturas e assim deveria ser vista (CUNHA, 2009a). 
Em suma, a docência, por ser uma atividade complexa, requer preparação dos professores, que precisam de formação pedagógica. A pedagogia é um campo teórico da prática educacional, e não se resume apenas à didática. Esta é uma das áreas da pedagogia (PIMENTA \& ANASTASIOU, 2002).

Os elementos constitutivos da atuação docente de um professor, como planejamento, organização da aula, metodologias e estratégias didáticas, os processos de avaliação, os objetivos educacionais, a relação aluno-professor, entre outros, não são conhecidos cientificamente pelos professores e futuros professores. Entre docentes brasileiros, assim como ocorre no exterior, predomina um despreparo e até um desconhecimento científico do que seriam os processos de ensino e de aprendizagem pelos quais estes se tornam responsáveis a partir do momento em que ingressam na sala de aula. (ALMEIDA \& PIMENTA, 2009; MASETTO, 2003).

Da mesma maneira que não basta saber o que se vai ensinar, o professor não pode apenas ter conhecimentos pedagógicos em detrimento dos conhecimentos técnicos (específicos) que serão ensinados, sendo que, nos processos de formação de professores, é preciso considerar a importância dos saberes das áreas de conhecimento (ninguém ensina o que não sabe), dos saberes pedagógicos (pois o ensinar é uma prática educativa que tem diferentes e diversas direções de sentido na formação do humano), dos saberes didáticos (que tratam da articulação da teoria da educação e da teoria de ensino para ensinar nas situações contextualizadas), dos saberes da experiência do sujeito professor (que dizem do modo como os sujeitos se apropriam do ser professor). Esses saberes se dirigem às situações de ensinar e com elas dialogam, revendo-se, redirecionando-se, ampliando-se e criando (PIMENTA \& ANASTASIOU, 2002).

Dada a complexidade da docência universitária, a formação inicial dos professores, muitas vezes mesmo que agregada à experiência profissional, não basta. O professor iniciante perceberá algumas carências formativas, algo que acontece também com professores mais experientes (GAETA \& MASETTO, 2013).
É fato que existem muitas ações de formação de professores, como grupos de discussão, workshops, pequenos cursos; há aqueles que tentam adquirir uma formação pedagógica por meio de leituras e trocas de experiências. Mas muito mais precisa ser feito; o ideal seria uma formação inicial e contínua institucionalizada para todos os professores universitários, uma vez que as pequenas ações existentes não estão sendo suficientes para se atingir o propósito almejado (ALMEIDA, 2012; FEIXAS, 2004; GIBBS, 2004).

Uma variável fundamental nas mudanças necessárias no cenário atual universitário está centrada no processo institucional de profissionalização docente, seja esta profissionalização inicial ou continuada. No caso das universidades públicas, os profissionais ingressam por meio de concursos públicos, que nem sempre objetivam o domínio de saberes pedagógicos necessários à docência em sua complexidade, restringindo-se às áreas de conhecimento a serem lecionadas (ANASTASIOU, 2009).

As ações individuais dos professores não adiantam mais; são necessárias ações institucionais. Com um fato indutor de mudanças, obviamente as universidades têm que definir estratégias que visam a ir além de simplesmente "melhorar a docência" (GIBBS, 2004). Muitas universidades europeias têm seus próprios programas de formação de professores novatos e experientes, e tais experiências possuem resultados bastante significativos (ALMEIDA, 2012; GIBBS, 2004; FEIXAS, 2004).

A formação continuada, sendo parte do desenvolvimento profissional dos professores, contribui não só para a constituição dos saberes que lhes permitem qualificar as suas maneiras de ensinar, mas também para a configuração da própria profissão docente (ALMEIDA, 2012). Diante de experiências de formação continuada de professores de nível superior, Anastasiou (2009) constata que as alterações nas práticas de docentes universitários participantes de processos formativos são mais evidentes quando vários ou todos os docentes de um curso recebem formação 
pedagógica. Sendo que, quando há a participação da maioria do corpo docente, as possibilidades de abrangência e sistematização de avanços são mais consistentes, visíveis e contagiantes.

No Brasil, segundo a Lei de Diretrizes e Bases (LDB) n. 9.394/1996 (BRASIL, 1996), a pósgraduação stricto sensu seria a responsável pela formação dos futuros professores universitários. Porém, não é o que se observa. A pós-graduação cumpre muito bem seu papel quando se trata de pesquisa acadêmica, mas não quando se trata da formação pedagógica dos futuros professores (ALMEIDA, 2012).

Se a especificidade e identidade da profissão docente é o ensino, é inadmissível que professores universitários que detenham o domínio do conhecimento em um campo científico não recebam uma formação mais condizente com as reais necessidades dos alunos e do "ser professor" (VEIGA, RESENDE \& FONSECA, 2006, p. 190).

Não se espera que todos os professores universitários se tornem especialistas em docência, mas todos necessitam de conhecimento profissional sobre a docência (ZABALZA, 2006).

Uma importante questão que surge é como fazer com que os professores universitários se interessem pela formação pedagógica, pois nem todos eles pensam que a formação docente seja algo importante; muitos acreditam que "ensinar se aprende ensinando" (ZABALZA, 2004, 2006). A docência precisa ser valorizada da mesma maneira que a pesquisa, ao mesmo tempo que os professores precisam ser "recompensados" de alguma maneira. O ideal é que a motivação para se aprimorar não venha apenas de uma obrigatoriedade ou da busca por uma recompensa, seja ela financeira, seja um status, mas que o professor queira se aprimorar, que haja uma motivação intrínseca. Além de que a reflexão como forma de indagação sobre a prática docente também conduz ao desenvolvimento profissional do professorado $\mathrm{e}$, indiretamente, à melhora organizacional $\mathrm{e}$ curricular do departamento/instituição de ensino (FEIXAS, 2004).

Almeida (2012) afirma que a comunidade acadêmica e a sociedade caminham rumo ao entendimento da formação como um processo que pressupõe crescimento pessoal, cultural e profissional, não na perspectiva de uma construção técnica, mas sim de um desenvolvimento crítico e reflexivo, uma vez que o sujeito tem de contribuir ao processo de sua própria formação com base nos conhecimentos, representações e experiências já existentes.

Todas as pessoas escolhem uma profissão e iniciam suas vidas profissionais com uma série de percepções, sentimentos, predisposições e um certo grau de experiência e formação, o que influi nas atitudes, expectativas e oportunidades futuras do profissional. $\mathrm{O}$ ambiente de trabalho pode oferecer os recursos apropriados para o desenvolvimento positivo do docente ou pode influenciar contrariamente em seu comportamento e realização de tarefas, de maneira que ele chega a frear seu desenvolvimento ou até a retroceder. $\mathrm{O}$ ambiente e o apoio institucional são fatores considerados chaves para o desenvolvimento profissional dos professores (FEIXAS, 2004).

\section{Formação de Professores nas Engenharias}

A essência do surgimento da área do conhecimento Educação em Engenharia vem da necessidade de melhorar a formação dos engenheiros, o que, naturalmente, passa pela qualificação e desenvolvimento profissional dos docentes.

A origem da Educação em Engenharia como uma área de conhecimento se deu por volta do ano de 1990. Especificamente nos Estados Unidos, um marco foi o lançamento de um programa pela National Science Foundation (NSF), para encorajar uma substancial reforma na graduação em engenharia no país. Assim como no Brasil atualmente, o que se queria era mais e melhores engenheiros. Um relatório da The National Science Board's, de 1986, já indicava que a pesquisa poderia promover o aprimoramento do ensino e da aprendizagem nos cursos de engenharia e em outros cursos de ciência, matemática e tecnologia, 
os chamados cursos STEM (do acrônimo Science, Technology, Engineering and Mathematics). Muitos outros relatórios subsequentes de importantes órgãos e universidades americanas continuavam a reafirmar a necessidade de pesquisa e mudanças na Educação em Engenharia, e desde então muito trabalho vem sendo realizado com o intuito de aprimorar a formação de engenheiros, sendo que o grande crescimento em pesquisa e publicações se deu por volta do ano 2000 (JESIEK, NEWSWANDER \& BORREGO, 2009).

Ainda na temática das origens da Educação em Engenharia como área de conhecimento, McMasters (2004) explora em seu trabalho o que a indústria, o governo e a academia podem fazer para garantir a formação de engenheiros que atendam aos requisitos do mercado de trabalho e as necessidades da sociedade. $\mathrm{O}$ autor apresenta uma lista de atributos desejados para os engenheiros da empresa Boeing, atributos estes que muitas vezes fogem dos currículos tradicionais de cursos de engenharia. Os atributos citados são: (1) bons conhecimentos das ciências fundamentais da engenharia; (2) bons conhecimentos de design e processos de manufatura; (3) conhecimentos básicos do contexto no qual a engenharia é praticada; (4) diversidade; (5) boas habilidade de comunicação; (6) perspectiva multidisciplinar de sistemas; (7) altos padrões éticos; (8) habilidade de pensar crítica e criativamente, independente e cooperativamente; (9) flexibilidade (habilidade e autoconfiança para se adaptar rapidamente a mudanças radicais); (10) curiosidade e desejo de aprender para a vida; e (11) profundo entendimento da importância do trabalho em equipe.

Estariam as instituições de ensino, as políticas governamentais e as empresas (em seus programas de treinamento e/ou seleção) prontas para formar, identificar e dar oportunidades para essas pessoas? Há uma grande desconexão entre o ensino médio (equivalente ao K-12 System, nos Estados Unidos, que tem o papel de preparar os alunos para a engenharia e quaisquer outras carreiras que queiram seguir), as universidades e a indústria. Tais dúvidas e constatações levam à proposição de algumas melhorias na Educação em Engenharia (MCMASTERS, 2004).

Precisamos fazer um trabalho muito melhor em determinar como educar os alunos para trabalhar em um ambiente moderno de engenharia, em vez de apenas pensar sobre quais habilidades específicas podem precisar para obter suas atribuições do primeiro emprego, ou como preparação para a pós-graduação em pesquisa (MCMASTERS, 2004, p. 361, tradução nossa).

As mudanças na tecnologia e na economia são extremamente rápidas e, como observado nos parágrafos anteriores, um novo perfil de engenheiro é necessário. Um profissional ético, com competências transversais, capaz de trabalhar em equipe, ser líder, entender o contexto no qual está inserido, saber se comunicar e, obviamente, ter as competências técnicas necessárias ao serviço que desenvolve. E como formar este profissional?

O grande chamado para a transformação dos engenheiros foi, então, a diminuição de alunos interessados em engenharia, juntamente com o aumento da necessidade de engenheiros no mercado de trabalho, as rápidas mudanças na tecnologia e a globalização (BENSON et al., 2010).

A área de conhecimento Educação em Engenharia tem por objetivo estudar, entender e propor soluções para tais questões. A Educação em Engenharia engloba desde a pré-engenharia (preparação dos estudantes para a engenharia, como despertar o gosto por ciências nas crianças etc.), a reestruturação dos currículos, a formação de professores e gestores, a inserção de novas metodologias de ensino, a interface com as empresas, entre outros atributos.

A necessidade de uma formação pedagógica para professores das engenharias e das outras áreas de exatas decorre então das mudanças que ocorreram nas universidades e também das transformações ocorridas no interior da própria engenharia ao longo dos anos. O perfil do engenheiro mudou muito nos últimos dois séculos, sendo que atualmente se espera que, além dos 
conhecimentos técnicos, o engenheiro seja um profissional cidadão com habilidades e competências que lhe possibilitem resolver as questões postas pelo mundo do trabalho.

No Brasil, não são inéditas as ações relacionadas ao aprimoramento e ao estudo do ensino de engenharia. Em 1973, foi criada a Abenge (Associação Brasileira de Educação em Engenharia), que busca a integração e a cooperação entre as Escolas de Engenharia, bem como o avanço da educação em Engenharia no Brasil. Tal instituição ainda promove o maior evento de educação em engenharia do país, o Cobenge (Congresso Brasileiro de Educação em Engenharia) (CORDEIRO, QUEIRÓS \& BORGES, 2010). Houve também iniciativas como o Reenge (Reengenharia do Ensino de Engenharia), o Paepe (Programa de Apoio ao Ensino de Engenharia) e o Promove (Programa de Modernização e Valorização das Engenharias).

Apesar de tantas iniciativas, este trabalho tentou mostrar a importância de políticas institucionais e da reflexão e conscientização por parte dos docentes e gestores para a melhoria das engenharias, e certamente tal constatação pode ser extrapolada para outras áreas do conhecimento.

\section{Agradecimento}

Agradecemos ao GNPq a concessão da bolsa de doutorado da autora.

\section{Notas}

1 Caracteriza-se pela heteronomia, por ser de elite e voltado para o conhecimento técnico. Cerceou a autonomia da universidade e instituiu a proteção do Estado (MORIN, 2000).

2 Caracteriza-se pela autonomia, por ser de elite e voltado para o conhecimento humanístico (MORIN, 2000).

\section{Referências Bibliográficas}

ALMEIDA, Maria Isabel de. Formação do Professor do Ensino Superior: Desafios e Políticas Institucionais. São Paulo: Cortez, 2012.

\& PIMENTA, Selma Garrido. "Pedagogia Universitária: Valorizando o Ensino e a Docência na Universidade de São Paulo". In: PIMENTA, Selma
Garrido \& ALMEIDA, Maria Isabel de (orgs.). Pedagogia Universitária. São Paulo: Edusp, 2009, pp. 13-38.

ANASTASIOU, Léa das Graças Camargos. "A Teoria e a Prática de Processos de Formação Continuada do Docente Universitário". In: PIMENTA, Selma Garrido \& ALMEIDA, Maria Isabel de (orgs.). Pedagogia Universitária. São Paulo: Edusp, 2009, pp. 39-70.

BARNETT, Ronald. Claves para Entender la Universidad en una Era de Supercomplejidad. Girona: Pomares, 2002.

BELLETATI, Valéria Cordeiro. Dificuldades de Alunos Ingressantes na Universidade Pública: Alguns Indicadores para Reflexões sobre a Docência Universitária. Tese (Doutorado em Educação), Faculdade de Educação, Universidade de São Paulo, 2011.

BENSON, Lisa C.; BECKER, Kurt; COOPER, Melanie M.; GRIFFIN, Hayden \& SMITH, Karl A. "Engineering Education: Departments, Degrees and Directions". International fournal of Engineering Education, vol. 26, n. 5, 2010, pp. 1042-1049.

BRASIL. "Lei N. 9.394, de 20 de Dezembro de 1996. Estabelece as Diretrizes e Bases da Educação Nacional”. D. O. de 23 de Dezembro de 1996, p. 27833. Disponível em: <http://www.planalto.gov.br/ccivil_03/ leis/19394.htm >. Acessado em 20 out. 2013.

CHAUÍ, Marilena. "A Universidade Pública sob Nova Perspectiva". Rev. Brasileira de Educaşão, n. 24, ANPED. São Paulo, set.-dez. 2003, pp. 5-15. Disponível em: <http://www.scielo.br/scielo.php?script=sci_arttext\&pid $=S 1413=24782003000300002-\& l n g=p t \& n r m-$ iso >. Acessado em 29 ago. 2013.

CORDEIRO, João Sérgio; QUEIRÓS, Pedro Lopes de \& BORGES Mario Neto. "Associação Brasileira de Educação em Engenharia (Abenge)". In: Instituto Nacional de Estudos e Pesquisas Educacionais Anísio Teixeira e Conselho Federal de Engenharia, Arquitetura e Agronomia. Trajetória e Estado da Arte da Formação em Engenharia, Arquitetura e Agronomia. Brasília: Instituto Nacional de Estudos e Pesquisas Educacionais Anísio Teixeira, 2010, pp. 119-128. Disponível em: $<$ http://portal.inep.gov.br/documents/186968/492049/ Trajet $\%$ C3 $\%$ B3ria+e+estado+da+arte+da + forma $\% \mathrm{C}$ $3 \% \mathrm{~A} 7 \% \mathrm{C} 3 \% \mathrm{~A} 3 \mathrm{o}+\mathrm{em}+$ engenharia $\% 2 \mathrm{C}+$ arquitetura+ e+agronomia $+\%$ E $2 \% 80 \% 93+\mathrm{Vol}+01 / 63 f f 032 \mathrm{e}-\mathrm{bf} 72$ 46f0-84d9-606d0b84ec3e?version=1.0>. Acessado em 20 jan. 2014.

GUNHA, Luiz Antônio. "Ensino Superior e Universidade no Brasil". In: LOPES, Eliane Marta Teixeira \& MENDES, Luciano (orgs.). 500 Anos de Educaşão no Brasil. Belo Horizonte: Autêntica, 2000, pp. 151-204.

CUNHA, Maria Isabel da. "Inovações Pedagógicas: o Desafio da Reconfiguração de Saberes na Docência Universitária". In: PIMENTA, Selma Garrido \& ALMEIDA, Maria Isabel de (orgs.). Pedagogia 
Universitária. São Paulo: Edusp, 2009a., pp. 211-236.

CUNHA, Maria Isabel da. "O Lugar da Formação do Professor Universitário: o Espaço da Pós-Graduação em Educação em Questão". Revista Diálogo Educacional, PUC-PR, vol. 9, 2009. Disponível em: <http://www2.pucpr.br/reol/index. php/DIALOGO?dd1 $=2585 \& d d 99=v i e w>$. Acessado em 20 out. 2013.

EZGURRA, Ana María. "Os Estudantes Recémingressados: Democratização e Responsabilidade das Instituições Universitárias". In: PIMENTA, Selma Garrido \& ALMEIDA, Maria Isabel de (orgs.). Pedagogia Universitária. São Paulo: Edusp, 2009, pp. 91-127.

FEIXAS, Mônica. "La Influencia de Factores Personales, Institucionales y Contextuales en la Trajectoria y el Desarrollo Docente de los Profesores Universitarios". Educar, n. 33, 2004, pp. 31-58.

GAETA, Cecília \& MASETTO, Marcos Tarciso. O Professor Iniciante no Ensino Superior: Aprender, Atuar e Inovar. São Paulo: Senac, 2013.

GIBBS, Graham. "Mejorar la Enseñanza y el Aprendizaje Universitario mediante Estrategias Institucionales". Educar, n. 33, 2004, pp. 11-30.

JESIEK, Brent K.; NEWSWANDER, Lynita K. \& BORREGO, Maura. "Engineering Education Research: Discipline, Community or Field?". Fournal of Engineering Education, 2009, pp. 39-52.

KRASILCHIK, Myriam. "Docência no Ensino Superior: Tensões e Mudanças". In: PIMENTA, Selma Garrido \& ALMEIDA, Maria Isabel de (orgs.). Pedagogia Universitária. São Paulo: Edusp, 2009, pp. 147-164.

- "Reformas e Realidade: o Caso do Ensino das Ciências". São Paulo em Perspectiva, vol. 14, n. 1, 2000. Disponível em: $<$ http://www.scielo.br/scielo.php?script $=$ sci arttext\&pid=S $0102-88392000000100010$ \& lng=en\&nrm=iso\&tlng=pt $>$. Acessado em 15 jan. 2014.

MARTINS, Carlos Benedito. "O Ensino Superior Brasileiro nos Anos 90". São Paulo em Perspectiva, vol. 14, n. 1, 2000, pp. 41-72.
MASETTO, Marcos Tarciso. Competência Pedagógica do Professor Universitário. São Paulo: Summus, 2003. 1998. Docencia na Universidade. Campinas: Papirus,

MCMASTERS, John H. "Influencing Engineering Education: One (Aerospace) Industry Perspective". International Fournal of Engineering Education, vol. 20, n. 3, 2004, pp. 353-371.

MORIN, Edgard. Complexidade e Transdisciplinaridade: a Reforma da Universidade e do Ensino Fundamental. Natal: EDUFRN, 2000.

PIMENTA, Selma Garrido \& ANASTASIOU, Léa das Graças Camargos. Docência no Ensino Superior. São Paulo: Cortez, 2002.

RIOS, Terezinha Azeredo. "Ética na Docência Universitária: a Caminho de uma Universidade Pedagógica?". In: PIMENTA, Selma Garrido \& ALMEIDA, Maria Isabel de (orgs.). Pedagogia Universitária: Caminhos para a Formação de Professores. São Paulo: Cortez, 2011, pp. 229-245.

RUÉ, Joan. "A Aprendizagem com Autonomia, Possibilidades e Limites". In: PIMENTA, Selma Garrido \& ALMEIDA, Maria Isabel de (orgs.). Pedagogia Universitária. São Paulo: Edusp, 2009, pp. 71-90.

SEVERINO, Antônio Joaquim. "Ensino e Pesquisa na Docência Universitária: Caminhos para a Integração". In: PIMENTA, Selma Garrido \& ALMEIDA, Maria Isabel de (orgs.). Pedagogia Universitária. São Paulo: Edusp, 2009, pp. 129-146.

VEIGA, Ilma Passos Alencastro; RESENDE, Lucia Maria Gonçalves de \& FONSECA, Marília. "Aula Universitária e Inovação". In: VEIGA \& CASTANHO (orgs.). Pedagogia Universitária: a Aula em Foco. Campinas: Papirus, 2006, pp. 161-191.

ZABALZA, Miguel. Competencias Docentes del Profesorado Universitario - Qualidad y Desarrollo Profesional. Madrid: Narcea, 2006.

La Enseñanza Universitaria: el Escenario y sus Protagonistas. Madrid: Narcea, 2004.

Publicado em 12/06/2018. 